\title{
ANALISIS EKUITAS MEREK LAPTOP PADA MAHASISWA INSTITUT PERTANIAN BOGOR
}

\author{
Analysis of Brand Equity of Laptop among Bogor Agricultural University Students \\ UJANG SUMARWAN ${ }^{1}$, RETNANINGSIH $^{1 *}$, HANISA RAHMINA FITRIYANA $^{2}$ \\ ${ }^{1}$ Staf Pengajar Departemen IImu Keluarga dan Konsumen, Fakultas Ekologi Manusia, \\ Institut Pertanian Bogor, Jalan Lingkar Kampus IPB Dramaga, \\ Bogor 16680 \\ ${ }^{2}$ Departemen Ilmu Keluarga dan Konsumen, Fakultas Ekologi Manusia, Institut Pertanian \\ Bogor, Kampus Dramaga, Bogor 16680
}

\begin{abstract}
The brand has role to bridge the consumers' expectations and companies' promises. Prestigious brand can be said to have strong brand equity. This research had objective to analyze brand equity of laptop products among Bogor Agricultural University (IPB) students. Meanwhile, the detail purposes in this research are: (1) to analyze the behavior in using the laptop products, (2) to analyze brand equity elements (brand awareness, brand association, perceived quality, and brand loyalty) among IPB students, and (3) to find out the correlation between top of mind and laptop brands that have been used by IPB students. This research used cross sectional study design with total sample 200 students. The determination of total samples in each faculty used proportional sampling. The process to select sample was executed by convenience sampling that was selecting the samples based on availability to fill up the questionnaire and interview that appropriated with the quota in each faculty. The laptop brand that has been mostly used and possessed is Acer. The duration of possessing the laptop mostly was 10 months until 18 months. Most of laptops were bought by parents in new products. On the brand awareness elements of brand product, Acer generally got the better spot, then it was followed by Toshiba, HP Compaq, and Axioo. The testing of brand association with using Cochran test showed that the smallest association was obtained to Acer brand. It was because the other brand, such as Toshiba, HP Compaq, and Axioo had all associations that adhere to consumers. The perceived quality that was tested by Customer Satisfaction Index (CSI), referred that index satisfaction of samples about Acer, Toshiba, and Axioo brand had satisfied level. Meanwhile, the samples that used HP Compaq had very satisfied level. The Importance Performance Analysis (IPA) showed that only Toshiba brand that was the most excellent in which none atribute which was fixed. For brand loyalty element, HP Compaq brand had the most high loyalty of consumer than the others. The Chi Square test showed that the correlation between top of mind and laptop brand that used was consistent that indicated top of mind was suit with laptop brand that used.
\end{abstract}

Key words: brand, brand equity, laptop, top of mind, usage behaviour

\section{PENDAHULUAN}

Seiring dengan perkembangan teknologi, penggunaan laptop semakin hari semakin populer dan memperlihatkan perkembangan yang cukup signifikan. Berbeda dengan komputer meja (desktop) yang dirancang untuk berada di tempat yang tetap, laptop dirancang agar dapat digunakan di mana pun pemiliknya berada. Karena itu, untuk seseorang dengan mobilitas tinggi, memiliki laptop lebih diminati dibanding memiliki komputer desktop.

Salah satu segmentasi yang menjadi target produsen laptop adalah mahasiswa. Bagi produsen, mahasiswa merupakan salah satu pasar yang potensial karena mahasiswa memiliki kegiatan yang membutuhkan bantuan laptop untuk menunjang kegiatannya. Laptop dapat berfungsi sebagai sarana penunjang pendidikan dan dapat pula sebagai sarana hiburan. 
Perkembangan penjualan yang cenderung mengalami peningkatan memicu produsen laptop dalam meramaikan pasar laptop. Dewasa ini, persaingan perusahaan untuk memperebutkan pelanggan tidak lagi terbatas pada atribut fungsional produk (seperti kegunaan produk), melainkan juga sudah dikaitkan dengan merek yang mampu memberikan citra khusus bagi pemakainya.

Fenomena persaingan yang ada membuat perusahaan menyadari suatu kebutuhan untuk mengeksploitasi sepenuhnya asetaset mereka, guna memaksimalkan kinerja perusahaan dan mengembangkan keuntungan kompetitif yang berkelanjutan (sustainable competitive advantage), yang berlandaskan kompetisi nonharga. Salah satu aset yang digunakan perusahaan untuk menguasai pasar adalah merek (Kotler 2003). Merek memegang peran yang sangat penting karena mengembangkan suatu merek akan terkait dengan janji (promise) dan harapan (expectation). Salah satu peran merek adalah menjembatani harapan konsumen pada saat perusahaan menjanjikan sesuatu pada konsumen. Merek yang prestisius dapat dikatakan memiliki ekuitas merek (brand equity) yang kuat.

Tujuan umum dari penelitian ini adalah untuk menganalisis ekuitas merek laptop pada mahasiswa IPB. Tujuan khusus dari penelitian ini adalah untuk menganalisis perilaku penggunaan laptop pada mahasiswa IPB; menganalisis elemen-elemen ekuitas merek laptop (kesadaran merek, asosiasi merek, persepsi kualitas, dan loyalitas merek) pada mahasiswa IPB; serta mengetahui hubungan top of mind dengan merek laptop yang digunakan mahasiswa IPB.

\section{METODE}

\section{Desain, Tempat, dan Waktu}

Desain penelitian ini adalah cross sectional study. Penelitian ini dilakukan di Institut Pertanian Bogor (IPB) yang berlokasi di Kampus IPB Dramaga. Pemilihan lokasi penelitian dilakukan secara sengaja (purposive sampling) berdasarkan pertimbangan bahwa IPB merupakan salah satu perguruan tinggi terbesar di Indonesia. Waktu pengambilan data dilakukan selama bulan Juni 2009.

\section{Jenis dan Teknik Pengumpulan Data}

Populasi dalam penelitian ini adalah mahasiswa mayor-minor IPB tahun ajaran 2008/2009 yang berjumlah 11.615 orang.
Berdasarkan rumus Slovin (Umar 2003), untuk memenuhi jumlah contoh minimal dalam penelitian ini yaitu sebanyak 155 orang, maka diambil contoh sebanyak 200 orang. Penentuan jumlah contoh setiap fakultas menggunakan proportional sampling, proses pemilihan contoh dilakukan secara convenience sampling yaitu contoh dipilih berdasarkan kesediaannya untuk mengisi kuesioner dan wawancara sesuai dengan kuota per fakultas.

Jenis data yang digunakan dalam penelitian ini terdiri dari data primer dan data sekunder. Data primer diperoleh dari wawancara dengan contoh dengan menggunakan kuesioner, yang meliputi data karakteristik individu dan keluarga responden, yaitu jenis kelamin, usia, lama studi, uang saku, besar keluarga; dan pertanyaanpertanyaan mengenai elemen-elemen ekuitas merek yang meliputi kesadaran merek, persepsi kualitas, asosiasi merek, dan loyalitas merek. Data sekunder diperoleh dari Direktorat Administrasi Pendidikan IPB, Direktorat Komunikasi dan Sumber Informasi IPB, Buku Panduan Sarjana IPB, studi literatur, serta bahan pustaka yang diambil dari hasil penelitian sebelumnya.

\section{Pengolahan dan Analisis Data}

Pengolahan data menggunakan Microsoft Excel dan SPSS for Windows. Data yang dikumpulkan dari kuesioner diolah melalui proses editing, coding, scoring, entry data, cleaning data, dan analisis data. Analisis data dalam penelitian ini menggunakan analisis deskriptif dan inferensia, yaitu uji Cochran, Customer Satisfaction Index (CSI), Importance Performance Analysis (IPA), Brand Switching Pattern Matrix, dan uji Chi Square.

\section{HASIL DAN PEMBAHASAN}

\section{Karakteristik Individu dan Keluarga}

Contoh paling banyak berjenis kelamin perempuan yaitu sebesar $61 \%$, sedangkan jumlah contoh laki-laki sebesar $39 \%$. Hal ini sesuai dengan proporsi jumlah mahasiswa IPB yaitu lebih banyak perempuan $(58,9 \%)$ daripada laki-laki $(41,1 \%)$ (Tabel 1). Menurut Hurlock (1980), mahasiswa termasuk ke dalam tahapan usia remaja akhir dan dewasa awal. Hasil penelitian menunjukkan usia contoh antara 17 sampai 23 tahun. Jumlah contoh yang terbesar adalah masa dewasa awal sebesar 98\%. Contoh paling banyak adalah mahasiswa pada semester 
delapan yaitu sebanyak $38,5 \%$ dan paling sedikit adalah mahasiswa pada semester dua yaitu sebesar 3\%. Hal ini dikarenakan mahasiswa semester delapan adalah yang paling banyak menggunakan laptop, yakni untuk menunjang dalam pengerjaan skripsi/tugas akhir.

Hampir seluruh contoh (96,5\%) memperoleh uang saku dari orang tua, dan sisanya berasal dari saudara/wali dan hasil usaha. Selain itu, contoh juga memperoleh uang saku tambahan, diantaranya dari beasiswa, mengajar, dan usaha (menjual pulsa dan menjaga rental komputer). Sebaran uang saku contoh per bulan berada pada kisaran antara Rp 200.000,00 sampai dengan $\mathrm{Rp} 2.000 .000,00$ dengan rata-rata Rp 743.010,80. Hampir separuh contoh $(48,5 \%)$ memiliki uang saku pada kategori sedang. Berdasarkan besar keluarga, BKKBN (1998) membagi keluarga ke dalam tiga kategori yaitu keluarga kecil, sedang, dan besar. Dalam penelitian ini sebagian besar contoh $(84,5 \%)$ termasuk dalam kategori keluarga sedang.

\section{Kepemilikan dan Penggunaan Laptop}

Dari keseluruhan contoh, yang memiliki laptop adalah sebesar $77,5 \%$ dan $22,5 \%$ tidak memiliki laptop. Berdasarkan merekmerek laptop yang dimiliki oleh contoh, Acer menempati urutan pertama yaitu sebesar $34,5 \%$; selanjutnya merek Toshiba (13\%), HP Compaq (9\%), Axioo (6,5\%), dan lain-lain sebesar $14 \%$ (Tabel 2).

Konsumen cenderung membeli suatu merek yang sudah dikenal, karena dengan membeli merek yang sudah dikenal mereka akan merasa aman dan terhindar dari berbagai risiko pembelian dengan asumsi bahwa merek yang sudah dikenal lebih dapat diandalkan (Durianto et al. 2004). Hal ini juga yang terjadi pada mahasiswa contoh yang sebagian besar menggunakan merek Acer. Merek Acer sudah dikenal di kalangan mahasiswa dengan harga yang cukup terjangkau dibandingkan dengan merek yang lain dengan fitur yang dapat memenuhi kebutuhan penggunanya.

Merek laptop yang digunakan hampir sama dengan merek yang dimiliki oleh contoh dengan adanya penambahan dari contoh yang tidak memiliki laptop. Hampir seluruh dari contoh (93,5\%) membeli laptop dalam keadaan baru. Sebagian besar contoh $(84,5 \%)$ membeli laptop oleh orang tua.
Tabel 1. Sebaran contoh berdasarkan karakteristik individu dan keluarga

\begin{tabular}{|c|c|c|}
\hline Keterangan & $\mathbf{n}$ & $\%$ \\
\hline \multicolumn{3}{|l|}{ Jenis Kelamin } \\
\hline Laki-laki & 78 & 31,0 \\
\hline Perempuan & 122 & 69,0 \\
\hline Total & 200 & 100,0 \\
\hline \multicolumn{3}{|l|}{ Usia } \\
\hline Remaja akhir & 4 & 2,0 \\
\hline Dewasa awal & 196 & 98,0 \\
\hline Total & 200 & 100,0 \\
\hline \multicolumn{3}{|l|}{ Semester } \\
\hline 2 & 6 & 3,0 \\
\hline 4 & 58 & 29,0 \\
\hline 6 & 59 & 29,5 \\
\hline 8 & 77 & 38,5 \\
\hline Total & 200 & 100,0 \\
\hline \multicolumn{3}{|l|}{ Uang Saku (Rp) } \\
\hline Rendah $(\leq 600.000)$ & 79 & 39,5 \\
\hline Sedang (600.001-1.200.000) & 97 & 48,5 \\
\hline Tinggi ( $\geq 1.200 .000)$ & 10 & 5,0 \\
\hline Tidak menjawab & 14 & 7,0 \\
\hline Total & 200 & 100,0 \\
\hline \multicolumn{3}{|l|}{ Besar Keluarga } \\
\hline $\operatorname{Kecil}(\leq 4)$ & 9 & 4,5 \\
\hline Sedang (5-7) & 169 & 84,5 \\
\hline Tinggi $(>7)$ & 22 & 11,0 \\
\hline Total & 200 & 100,0 \\
\hline
\end{tabular}

Tabel 2. Sebaran contoh berdasarkan merek laptop yang dimiliki dan yang digunakan

\begin{tabular}{lrrrr}
\hline \multirow{1}{*}{ Merek } & \multicolumn{2}{c}{$\begin{array}{c}\text { Kepemilikan } \\
\text { Laptop }\end{array}$} & $\begin{array}{c}\text { Penggunaan } \\
\text { Laptop }\end{array}$ \\
\cline { 2 - 5 } & $\mathbf{n}$ & $\%$ & $\mathbf{n}$ & $\%$ \\
\hline Acer & 69 & 34,5 & 101 & 50,5 \\
Toshiba & 26 & 13,0 & 33 & 16,5 \\
HP Compaq & 18 & 9,0 & 21 & 10,5 \\
Axioo & 13 & 6,5 & 14 & 7,0 \\
HP & 5 & 2,5 & 6 & 3,0 \\
Zyrex & 4 & 2,0 & 4 & 2,0 \\
Asus & 3 & 1,5 & 4 & 2,0 \\
Dell & 3 & 1,5 & 3 & 1,5 \\
Byon & 2 & 1,0 & 2 & 1,0 \\
Ben Q & 2 & 1,0 & 2 & 1,0 \\
E-Machine & 2 & 1,0 & 2 & 1,0 \\
Fujitsu & 2 & 1,0 & 2 & 1,0 \\
Lenovo & 2 & 1,0 & 2 & 1,0 \\
Sony Vaio & 2 & 1,0 & 2 & 1,0 \\
A Note & 1 & 0,5 & 1 & 0,5 \\
Apple & 1 & 0,5 & 1 & 0,5 \\
\hline \multicolumn{1}{c}{ Total } & 155 & 100,0 & 200 & 100,0 \\
\hline
\end{tabular}

Lamanya kepemilikan laptop. Kepemilikan laptop sangat marak pada beberapa tahun terakhir. Lamanya kepemilikan laptop oleh contoh berada pada selang antara 1 sampai 72 bulan dengan rata-rata 11,98 bulan. Lama kepemilikan laptop yang paling banyak adalah selama 10-18 bulan, yaitu sebesar 45,2\% (Tabel 3 ). 
Contoh memiliki laptop dalam kurun waktu baru-baru ini atau pada saat maraknya laptop di Indonesia dan pada saat contoh memasuki masa-masa perkuliahan untuk menunjang tugas-tugas kuliah. Semakin lama kepemilikan laptop maka contoh semakin mengenal merek laptop tersebut sehingga contoh mengetahui kinerja dari laptop yang dimilikinya.

Tabel 3. Sebaran contoh berdasarkan lamanya kepemilikan laptop

\begin{tabular}{|c|c|c|}
\hline Lamanya Kepemilikan (bl) & $\mathbf{n}$ & $\%$ \\
\hline $1-9$ & 39 & 25,2 \\
\hline $10-18$ & 70 & 45,2 \\
\hline $19-27$ & 32 & 20,6 \\
\hline $28-36$ & 10 & 6,5 \\
\hline $37-45$ & 0 & 0,0 \\
\hline $46-54$ & 1 & 0,6 \\
\hline $55-63$ & 1 & 0,6 \\
\hline $64-72$ & 2 & 1,3 \\
\hline Total & 155 & 100,0 \\
\hline
\end{tabular}

\section{Sumber Informasi}

Informasi yang dipegang konsumen mengenai produk dalam hal ini laptop akan sangat mempengaruhi pola pembelian produk tersebut (Engel et al. 1994). Menurut Sumarwan (2004), seorang konsumen seringkali meminta pendapat mengenai produk atau jasa kepada teman dan keluarga. Proses komunikasi biasanya berlangsung secara lisan. Pendapat teman atau keluarga bagi konsumen seringkali mempengaruhi pengambilan keputusan konsumen dalam membeli produk atau jasa.

Sumber informasi yang paling banyak diperoleh contoh adalah media cetak, baik dari majalah atau surat kabar, yaitu sebesar $61 \%$. Selain itu, memperoleh informasi dari teman atau keluarga sebesar 24\% (Tabel 4). Informasi diperoleh contoh dari membaca surat kabar atau majalah sehingga dapat mengetahui merek-merek laptop tersebut dari media cetak.

Tabel 4. Sebaran contoh berdasarkan sumber informasi merek laptop

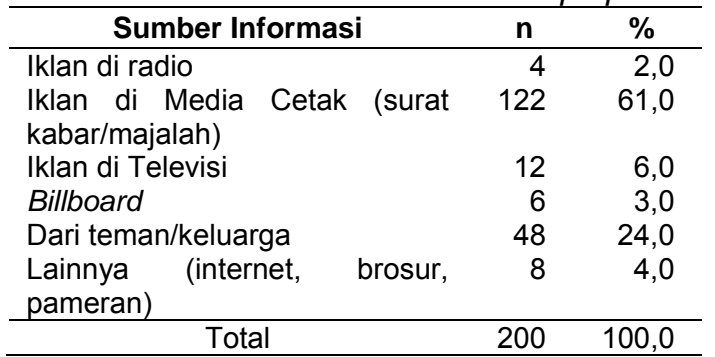

\section{Ekuitas Merek}

Ekuitas merek (brand equity) adalah seperangkat aset dan liabilitas merek yang terkait dengan suatu merek, nama, simbol, yang mampu menambah atau mengurangi nilai yang diberikan oleh sebuah produk atau jasa, baik pada perusahaan maupun pada pelanggan (Aaker 1991). Ekuitas merek (brand equity) dapat dikelompokkan dalam lima kategori, yaitu kesadaran merek (brand awareness), asosiasi merek (brand association), persepsi kualitas (perceived quality), loyalitas merek (brand loyalty), dan aset-aset merek lainnya (other proprietary brand assets).

Kesadaran Merek (Brand Awareness). Menurut Aaker (1991), kesadaran merek adalah kemampuan konsumen untuk mengenali suatu merek sebagai bagian dari kategori produk tertentu. Top of mind menggambarkan merek yang pertama kali diingat konsumen atau pertama kali disebut ketika yang bersangkutan ditanya tentang suatu kategori produk. Merek yang berada pada tingkat ini merupakan merek yang utama dalam benak konsumen, sehingga dalam situasi pembelian merek lain tidak diperhitungkan. Lebih dari separuh contoh $(52 \%)$ menyebutkan Acer sebagai merek laptop yang pertama kali diingat. Merek yang memiliki top of mind tinggi akan memiliki value (nilai) yang tinggi pula. Apabila suatu merek tidak tersimpan baik dalam benak konsumen, maka merek tersebut tidak dipertimbangkan oleh konsumen dalam mengambil keputusan pembelian.

Acer merupakan market leader laptop di Indonesia. Hal ini disebabkan merek Acer merupakan produk yang memiliki konsumen terbesar di Indonesia dengan jumlah penjualan yang selalu meningkat. Menurut data yang dikeluarkan lembaga riset Gartner, pada kuartal pertama tahun 2007, penjualan Acer Indonesia mencatat 134.386 unit, yang terdiri dari komputer desktop dan notebook, dengan pertumbuhan Year on Year mencapai 23,6\%. Pada tahun 2008 tercatat total penjualan Acer mencapai 491.657 unit atau meningkat $20,1 \%$ dari tahun 2007 (Suryadhi 2009).

Brand recall mencerminkan merek apa yang diingat konsumen setelah menyebutkan merek yang pertama kali disebut. Aaker (1991) menyatakan bahwa pada tingkatan ini disebut juga dengan pengingatan kembali tanpa bantuan (unaided recall). Kategori brand recall ditempati oleh Toshiba yaitu sebesar 33\% (Tabel 5). 
Tabel 5. Sebaran contoh berdasarkan puncak pikiran (top of mind) dan brand recall merek laptop

\begin{tabular}{lrrrr}
\hline \multirow{2}{*}{ Merek } & \multicolumn{2}{c}{ Top of Mind } & \multicolumn{2}{c}{ Brand Recall } \\
\cline { 2 - 5 } & $\mathbf{n}$ & \multicolumn{1}{c}{$\%$} & \multicolumn{1}{c}{$\mathbf{n}$} & \multicolumn{1}{c}{$\%$} \\
\hline Acer & 104 & 52,0 & 59 & 29,5 \\
Toshiba & 39 & 19,5 & 66 & 33,0 \\
HP Compaq & 20 & 10,0 & 11 & 5,5 \\
Apple & 10 & 5,0 & 15 & 7,5 \\
Axioo & 10 & 5,0 & 5 & 2,5 \\
Lain-lain & 17 & 8,5 & 44 & 22,0 \\
\hline \multicolumn{1}{c}{ Total } & 200 & 100,0 & 200 & 100,0 \\
\hline
\end{tabular}

Jumlah orang yang harus diingatkan akan keberadaan merek Acer (brand recognition) adalah sebanyak 2,5\% dari 200 orang contoh, sedangkan untuk merek Toshiba, HP Compaq, Axioo secara berturutturut yaitu $6,5 \%, 29 \%$, dan $44,5 \%$. Hal ini membuktikan bahwa ingatan contoh akan keberadaan merek Acer lebih baik. Merek Acer dan Toshiba adalah merek yang sudah dikenal contoh sehingga persentase contoh yang perlu diingatkan kembali (brand unaware) jumlahnya kecil. Merek lainnya yaitu HP Compaq dan Axioo mempunyai brand unaware masing-masing sebesar 1,5\% dan $10,5 \%$ yang menunjukkan bahwa sejumlah contoh tersebut tidak mengenal merek ini sama sekali (Tabel 6).

Tabel 6. Sebaran contoh berdasarkan pengenalan merek (brand recognition) dan brand unaware laptop

\begin{tabular}{|c|c|c|c|c|}
\hline \multirow[t]{2}{*}{ Merek } & \multicolumn{2}{|c|}{$\begin{array}{c}\text { Brand } \\
\text { Recognition }\end{array}$} & \multicolumn{2}{|c|}{$\begin{array}{c}\text { Brand } \\
\text { unaware }\end{array}$} \\
\hline & $\mathrm{n}$ & $\%$ & $\mathrm{n}$ & $\%$ \\
\hline Acer & 5 & 2,5 & 0 & 0,0 \\
\hline Toshiba & 13 & 6,5 & 0 & 0,0 \\
\hline HP Compaq & 58 & 29,0 & 3 & 1,5 \\
\hline Axioo & 89 & 44,5 & 21 & 10,5 \\
\hline
\end{tabular}

Asosiasi Merek (Brand Association). Setelah dilakukan uji reliabilitas, terdapat sembilan butir atribut asosiasi dari 13 butir asosiasi yang ada, yaitu merek terkenal, produk berkualitas, variasi ukuran, memiliki prestise, diproduksi perusahaan yang inovatif, model yang beraneka ragam, garansi yang relatif lama, kemudahan layanan perbaikan, dan tingginya harga jual kembali. Hasil pengukuran asosiasi merek dengan menggunakan uji Cochran menunjukkan bahwa laptop merek Acer memiliki asosiasi paling sedikit (8) dibandingkan dengan merek lain (seperti Toshiba, HP Compaq, Axioo) yang memiliki semua asosiasi yang melekat pada konsumen. Hasil analisis asosiasi ini tidak sejalan dengan jumlah pengguna laptop merek Acer yang menempati urutan pertama. Hal ini diduga laptop merek Acer sudah melekat di benak konsumen sehingga konsumen mengabaikan asosiasi yang ada pada Acer.

Keberhasilan merek Acer ditunjukkan oleh asosiasi merek yang tinggi menunjukkan bahwa merek ini mampu membaca karakter pembeli laptop di Indonesia dan cukup jeli dalam membuat spesifikasi laptop pada segmen konsumen secara umum. Laptop Acer dijual di banyak toko yang tesebar di seluruh Indonesia baik offline maupun online, serta sudah lama bermain di pasar laptop Indonesia. Untuk masalah layanan purnajual para konsumen tidak khawatir lagi karena service center-nya cukup banyak. Namun, salah satu asosiasi merek pada Acer yang levelnya masih kurang bagus adalah harga jual kembali Acer yang lebih rendah dibandingkan merek laptop lainnya.

\section{Persepsi Kualitas (Perceived Quality)}

Persepsi kualitas adalah persepsi konsumen terhadap keseluruhan kualitas atau keunggulan suatu produk atau jasa layanan yang berkenaan dengan apa yang diharapkan oleh konsumen (Aaker 1991). Setelah dilakukan uji reliabilitas, atribut persepsi kualitas yang diteliti dalam penelitian ini adalah fitur lengkap, merek terkenal, teknologi canggih, mudah diperoleh, mudah mengoperasikan, variasi ukuran, variasi model, memiliki prestise, awet atau tahan lama, garansi yang relatif lama, dan kemudahan layanan perbaikan.

Dengan menggunakan analisis Customer Satisfaction Index (CSI), diperoleh hasil bahwa indeks kepuasan contoh terhadap merek Acer $(0,79)$, Toshiba $(0,77)$, dan Axioo $(0,78)$ berada pada predikat "puas" (berada pada rentang 0,66-0,80). HP Compaq berada pada predikat "sangat puas" dengan indeks kepuasan contoh sebesar 0,82 (berada pada rentang 0,81-1,00). Berdasarkan Importance Performance Analysis (IPA), atribut yang perlu perbaikan pada Acer adalah awet atau tahan lama, sedangkan Toshiba tidak ada atribut yang diperbaiki, HP Compaq perlu perbaikan pada atribut teknologi canggih, dan Axioo perlu perbaikan pada atribut variasi ukuran.

\section{Loyalitas Merek (Brand Loyalty)}

Tabel 7 menggambarkan merek HP Compaq memiliki nilai terendah pada 
tingkatan switcher yaitu sebesar 9,5\%. Pada tingkatan habitual buyer, merek Axioo memiliki persentase paling tinggi yaitu $35,7 \%$. Pada tingkatan satisfied buyer dan liking the brand, merek HP Compaq memiliki persentase jumlah contoh yang merasa puas dan disukai paling tinggi yaitu sebesar $85,7 \%$. Merek HP Compaq memiliki nilai tertinggi pada tingkatan committed buyer yaitu sebesar $66,7 \%$. Secara keseluruhan ada loyalitas merek dan bentuk piramida loyalitas, HP Compaq menjadi merek yang paling baik dibandingkan dengan tiga merek lainnya.

Tabel 7. Perbandingan hasil masing-masing tingkatan dari tiap merek

\begin{tabular}{lcccc}
\hline & \multicolumn{4}{c}{ Merek } \\
\cline { 2 - 5 } \multicolumn{1}{c}{ Level } & $\begin{array}{c}\text { Acer } \\
\text { (\%) }\end{array}$ & $\begin{array}{c}\text { Toshiba } \\
\text { (\%) }\end{array}$ & $\begin{array}{c}\text { HP } \\
\text { Compaq } \\
\text { (\%) }\end{array}$ & $\begin{array}{c}\text { Axioo } \\
\text { (\%) }\end{array}$ \\
\hline Committed buyer & 35,6 & 48,5 & 66,7 & 35,7 \\
Liking the brand & 49,5 & 66,7 & 85,7 & 64,3 \\
Satisfied buyer & 60,4 & 81,8 & 85,7 & 78,6 \\
Habitual buyer & 30,7 & 33,3 & 23,8 & 35,7 \\
Switcher & 48,5 & 30,3 & 9,5 & 35,7 \\
\hline
\end{tabular}

\section{Perpindahan Laptop}

Informasi yang diperoleh dari data-data di atas diperkuat pula dengan hasil analisis brand switching pattern matrix atau matriks perpindahan merek pada Tabel 8. Dari 101 pengguna merek Acer, terdapat $51,5 \%$ yang akan tetap memakai Acer dan 48,5\% akan berpindah ke merek lain. Pada pengguna laptop Toshiba, terdapat $69,7 \%$ yang akan tetap memakai Toshiba dan 30,3\% akan berpindah lain. Untuk pengguna laptop HP Compaq, sebesar 90,5\% akan tetap memakai HP Compaq dan hanya 9,5\% yang akan berpindah ke merek lain. Selanjutnya, untuk pengguna laptop Axioo, terdapat $64,3 \%$ akan tetap memakai Axioo dan 35,7\% akan berpindah merek lain. Perpindahan konsumen ke merek lain diduga karena memiliki kualitas yang lebih baik dari merek yang digunakan saat ini.

Pada pengguna HP Compaq, kemungkinan perpindahan ke merek lain hanya sebesar 10\% (Tabel 8). Dilihat dari persentase contoh yang tidak loyal (percentage of unloyal) juga menghasilkan kesimpulan yang sama dengan urutan yang sama. Hal ini menunjukkan bahwa konsumen laptop dengan merek HP Compaq memiliki tingkat loyalitas yang paling tinggi dibandingkan dengan merek lain. Secara keseluruhan, baik dengan pendekatan sikap maupun perilaku, merek HP Compaq menunjukkan loyalitas konsumen yang paling tinggi dibandingkan dengan merek lain.

Tabel 8. Kemungkinan perpindahan merek (probabilitas brand switching) laptop

\begin{tabular}{lcccc}
\hline Merek & $\begin{array}{c}\text { Kemungkinan } \\
\text { Perpindahan ke } \\
\text { Merek Lain (\%) }\end{array}$ & $\begin{array}{c}\text { Persentase } \\
\text { Contoh } \\
\text { yang Tidak } \\
\text { Loyal (\%) }\end{array}$ & $\begin{array}{c}\text { Laju } \\
\text { Penusutan } \\
\text { (\%) }\end{array}$ & $\begin{array}{c}\text { Per- } \\
\text { pindahan } \\
\text { Merek } \\
\text { (\%) }\end{array}$ \\
\hline Acer & 66,4 & 48,5 & 17,9 & 48,5 \\
\hline Toshiba & 31,8 & 30,3 & 1,5 & 30,3 \\
\hline HP & 10,0 & 9,5 & 0,5 & 9,5 \\
Compaq & 44,2 & 35,7 & 8,5 & 35,7 \\
\hline Axioo & & & & \\
\hline
\end{tabular}

\section{Hubungan Top of Mind dengan Laptop yang Digunakan}

Merek Laptop yang menjadi top of mind merupakan laptop yang banyak digunakan oleh contoh. Hal ini sesuai dengan definisi top of mind yang menggambarkan merek yang pertama kali diingat oleh contoh atau merek yang pertama kali disebut ketika contoh ditanya tentang suatu produk. Top of mind merupakan merek yang melekat pada konsumen sehingga banyak yang menggunakan laptop dengan merek tersebut. Merek laptop yang menjadi tiga urutan teratas dalam top of mind adalah Acer, Toshiba, HP Compaq. Hasil uji Chi Square menunjukkan adanya hubungan antara top of mind dengan merek laptop yang digunakan $(p<0,05)$ dengan nilai $p=0,000$. Top of mind berbanding lurus dengan merek laptop yang digunakan.

\section{KESIMPULAN DAN SARAN}

\section{Kesimpulan}

Merek laptop yang paling banyak dimiliki dan digunakan mahasiswa adalah Acer. Lama kepemilikan laptop contoh yang paling banyak adalah selama 10-18 bulan yaitu sebesar $45,2 \%$. Cara pembelian laptop pada contoh sebagain besar dibelikan oleh orang tua dan dalam keadaan baru.

Pada elemen kesadaran merek (brand awareness) untuk produk laptop merek Acer secara umum mendapat tempat yang lebih baik. Hasil pengukuran asosiasi merek dengan menggunakan uji Cochran menunjukkan bahwa asosiasi yang paling sedikit terdapat pada laptop merek Acer sebanyak delapan asosiasi, sedangkan merek lain, seperti Toshiba, HP Compaq, dan Axioo memiliki semua asosiasi yang melekat pada konsumen. Pada persepsi 
kualitas yang diuji dengan menggunakan Customer Satisfaction Index (CSI), indeks kepuasan contoh terhadap merek Acer, Toshiba, dan Axioo berada pada predikat "puas", sedangkan HP Compaq berada pada predikat "sangat puas". Uji dengan menggunakan Importance Performance Analysis (IPA), menunjukkan hanya merek laptop Toshiba tidak ada atribut yang diperbaiki. Untuk elemen loyalitas merek, merek HP Compaq menunjukkan loyalitas konsumen yang paling tinggi dibandingkan lainnya.

Hasil uji Chi Square menunjukkan adanya hubungan antara top of mind dengan merek laptop yang digunakan $(p<0,05)$ dengan nilai $p=0,000$. Top of mind berbanding lurus dengan merek laptop yang digunakan.

\section{Saran}

Produsen masing-masing merek laptop sebaiknya mengusahakan agar produknya mempunyai asosiasi-asosiasi pembentuk brand image yang berbeda dari yang lain dan meningkatkan kemampuannya pada asosiasi-asosiasi yang telah terbentuk agar tetap bertahan dan lebih baik. Hal ini dapat dilakukan antara lain dengan meningkatkan promosi, meningkatkan kualitas produk dan memberikan informasi tentang produk secara lebih jelas.

Produsen masing-masing merek laptop sebaiknya mempertahankan dan meningkatkan persepsi kualitas di benak konsumen. Perusahaan disarankan bersedia menerima masukan dan kritik dari konsumen mengenai kualitas produknya sehingga tercapai kesesuaian antara tingkat kepentingan atau harapan dari konsumen dengan kinerja dari produknya.

Selain itu, sebaiknya produsen memelihara dan meningkatkan loyalitas merek, antara lain dengan menjaga hubungan yang saling menguntungkan dengan konsumen dan menjaga kedekatan dengan konsumen secara berkesinambungan dengan cara meningkatkan promosi secara terus menerus, memberikan imbalan atas loyalitas konsumen, seperti bonus atau undian berhadiah serta menerima masukan dan kritik konsumen.

Sementara itu, konsumen sebaiknya mengetahui terlebih dahulu spesifikasi laptop yang akan dibeli, sehingga setelah pemakaian konsumen akan tetap loyal dengan produk yang digunakan. Iklan merupakan media sangat efektif untuk memasarkan suatu produk kepada calon konsumen atau pelanggan potensial.

\section{DAFTAR PUSTAKA}

Aaker D. 1991. Managing Brand Equity Capitalizing on the Value of a Brand Name. New York: The Free Press.

BKKBN. 1998. Kamus Istilah Kependudukan Keluarga Berencana Keluarga Sejahtera. Kantor Menteri Negara Kependudukan. Jakarta: Badan Koordinasi Keluarga Berencana Nasional.

Durianto D., Sugiarto, \& Sitinjak T. 2004. Strategi Menaklukan Pasar Melalui Riset Ekuitas dan Perilaku. Jakarta: PT. Gramedia Pustaka Utama.

Budiman, L.J. 2004. Brand Equity Ten Strategi Memimpin Pasar. Jakarta: PT. Gramedia Pustaka Utama.

Engel J.F., Blackwell R.D., \& Miniard P.W. 1994. Perilaku Konsumen Jilid 1. Jakarta: Binarupa Aksara.

Sumarwan U. 2004. Perilaku Konsumen Teori dan Penerapannya dalam Pemasaran. Jakarta: Ghalia Indonesia dengan MMA IPB.

Suryadhi A. Acer Kuasai Pasar Notebook Indonesia.http://www.detikinet.com. \{terhubung berkala] [20 Agustus 2009].

Susanto A.B. 2004. Power Branding Membangun Merek Unggul dan Organisasi Pendukungnya. Bandung: PT. Mizan Publika.

Umar H. 2003. Riset Pemasaran dan Perilaku Konsumen. Jakarta: Gramedia Pustaka Utama.

\footnotetext{
${ }^{*}$ Korespondensi :

Telp : +62-2518628303

Email : lunafisa@yahoo.com
} 